\title{
Effectiveness of Cognitive Restructuring in the Management of Mathophobia Among Secondary School Students in Khana L.G.A of Rivers State, Nigeria
}

\author{
Ernest-Ehibudu. Ijeoma Regina \\ Wayii, Augustine Lezorgia \\ Dept of Educational Psychology, Guidance and Counselling \\ University of Port Harcourt, Rivers State, Nigeria
}

Doi: 10.19044/esj.2017.v13n32p260 URL:http://dx.doi.org/10.19044/esj.2017.v13n32p260

\begin{abstract}
This study was developed and conducted to test the effect of cognitive restructuring in the management of mathophobia (that is, Mathematics anxiety) among secondary school students in Khana Local Government Area of Rivers State, Nigeria. To guide the study, two research questions and two null hypotheses were formulated for testing at 0.05 level of significance. In executing the study, the pre-test, post-test, and control group experimental research design was adopted using a randomized sample of 120 SS2 students drawn from three public secondary schools only. The researchers developed an instrument titled "Mathematics Diagnostic Questionnaire" (MDQ) which was adequately assessed for validity and reliability and was used in collecting pre-test and post-test data for the cognitive restructuring and control groups. Data analysis was done using mean, and standard deviation for the research questions, while independent sample and paired sample t-test were used for the hypotheses. The result obtained showed that the cognitive restructuring was significantly effective in the management of mathophobia among secondary school students. There is a slight reduction in the effect of cognitive restructuring during follow-up; there is a statistical significant difference in the mathophobic level of students treated with cognitive restructuring and those in the control group. Based on the major findings, recommendations were made among which is that functional guidance and counselling centers be established at all educational levels and be manned by professional counsellors who are competent in cognitive restructuring techniques to assist those who have mathophobia and other maladaptive behaviours. Suggestions for further study were made.
\end{abstract}


Keywords: Cognitive Restructuring, Management, Mathophobia, Rivers State

\section{Introduction}

The researchers have observed with dismay the level of abysmal poor performance of students in Mathematics assessments. A closer look at these students got them worried because most of them were doing excellently well in other subjects which means that they were not dull students. However, when it comes to the issue of Mathematics, their attitude and performance change drastically. This has raised concern for Mathematics teachers who claim to have tried their best in the possible approaches they know.

Mathematics is an unavoidable subject for all students. Most courses require a credit pass and only a few need a pass. Indeed, mathematical computation is the oil that maintains the machinery of society. However, some students try to circumvent things that seem tasking and challenging. Those who hate mathematics would not want it discussed. Some students exclaim, "We hate Mathematics" "can't we do something else?" Part of their escape process is to imagine it does not exist. However, Mathematics is an inescapable aspect of life. It is such an important subject that has been made compulsory for admitting candidates into almost all the disciplines in our tertiary institutions in Nigeria. Consequently, for students to attain success in their desired academic career, they are required to pass the subject appropriately with at least a credit pass.

According to Perry (2004), mathophobia (Mathematics anxiety) refers to dread of Mathematics that can interfere with manipulating numbers and solving mathematical problems in a wide variety of ordinary life and academic situation. In a similar way, Ashcraft (2002:182) avers that Mathophobia (Mathematics anxiety) is "a feeling of tension, apprehension, or fear that interferes with Mathematics performance". This implies that mathophobia is a trend that is regularly considered while examining the problems of students in Mathematics. Also, Bamidele (2005) expresses that the general impression of students is that Mathematics is an awful subject, but paradoxically it is the foundation for all scientific processes. This connotes that increasing sophistication of society and technological advancement make Mathematics ever more indispensable in the society.

However, research has established that lots of students have difficulty in learning which could lead to their poor grade in Mathematics. Some students in Nigeria owing to Mathophobia may possibly experience tension and stress that may weaken their intellectual capacity when it comes to solving for answer to mathematical assignments. This principally describes the academic challenge encountered by students as discovered by their abysmal awful performance in Mathematics in WAEC and NECO from 2008 to 2014. 
Hence from available record, it was noted that in 2008, only 13.76 per cent of 1,369,142 candidates had credit pass in Mathematics; In 2009 NECO/GCE examinations, only 1.8 percent of 236, 613 candidates that sat for the examinations across 1,708 centers had credit pass Mathematics. Still that year, candidates who sat for SSCE did not do well. In fact, out of 1,373,009 candidates, only 25.99 percent had credit pass in Mathematics. Again, out of $1,184,907$ candidates that sat for 2009 NECO internal examination, only 10.68 percent had credit pass in Mathematics. Furthermore, in June/July 2010 SSCE conducted by NECO, 24 percent did not pass Mathematics. In NECO June/July 2011 SSCE school-based examination, less than 25 per cent of the 1,160,561 candidates had credit pass in Mathematics across the country. 2011 Nov/Dec (GCE) NECO results recorded a mere 11.3 percent credit pass in Mathematics. Moreover, only 38.81 percent of 1,695,878 candidates that for the May/June 2012 WASSCE, obtained credit pass in Mathematics (Adesulu, 2012). In 2013, only 889,636 out of 1,689,188 candidates that sat for WAEC obtained a credit pass in Mathematics (Eguridu, 2013). In 2014, out of 1,692,435 candidates that sat for the examination, only 529,425 candidates got a credit pass in Mathematics (Eguridu, 2014). This development calls for concern among stakeholders and the speedy intervention to salvage this ugly condition, which is the focus of this study.

Consequent upon this fact, this research work is intended to evaluate the effect of a behaviour modification technique in managing mathophobia among secondary school students in Khana Local Government Area of Rivers State. Hence, cognitive restructuring is employed in this study. The choice of a cognitive restructuring strategy is due to the current trend in literature of experimental investigations of phobia (mathophobia). It is becoming apparent to researchers that cognitive restructuring as a technique can bring about changes in a person's thinking or cognitive processes (Kleinkneckt, 1986; Antoni, 2003; Asikhia, 2014). Thus, the task of the therapy involves identifying faulty thought patterns (fear of Mathematics) and replacing them with more adaptive cognition. Cognitive restructuring is a type of therapeutic technique, which refutes one's irrational ideas and replaces them with rational ones. Dibatolo, Frost, Dixon \& Almodorar (2001:168) defined cognitive restructuring as "employing self-statements, arguments, and disputations to make the client see irrationality in his or her behaviour and to be able to devise positive alternative ways to such irrationality in case the urge arises in the future". The assumption underlying this strategy is that disorders like phobia result from inappropriate irrational or self-defeating thoughts or belief.

Since most teachers assume they have done their bit in addressing the issue of fear for Mathematics without much success. The researchers, being counsellors feel that behaviour modification technique could remedy this case. 
It is against this background that they sought to examine the effect of cognitive restructuring $(\mathrm{C} / \mathrm{R})$ in the management of mathophobia $2, \mathbf{2}$.

\section{Research Questions}

The following research questions were answered to obtain the findings or results of the study:

1. What is the effect of cognitive restructuring in the management of mathophobia among secondary school students?

2. To what extent is the effect of cognitive restructuring technique in the management of mathophobia among secondary school?

\section{Hypotheses}

The following null hypotheses were tested at 0.05 level of significance, have been formulated to guide this study.

1. There is no significant difference between students treated with cognitive restructuring and those in the control group.

3. There is no significant difference in the post and follow-up assessment of students treated with cognitive restructuring technique.

\section{Literature review}

The term "phobia" originated from the Greek word "phobos" which means "fear of something". According to Roedigerill, Rushton, Calpaldi, and Paris (1984) and Hall (1997), phobia is a type of anxiety disorder, the most common of all the mental disorders. The other ones are Generalized Anxiety Disorder (GAD), Panic Disorder (PD), Post-Traumatic Stress Disorder (PTSD), and Obsessive-Compulsive Disorder (OCD). Anxiety disorders are usually described by the tendencies of anxiety under challenging situations, avoidance responses towards worrisome stimuli, the deficit in social relationships and a sense of distress associated responses (Nwankwo, 2006). Awujo, Ugwu and Amadi (2011) described phobic symptoms as, nausea, irritability, self defeating thoughts, mood swing, muscle tension, avoidance attitude, shouting urge, body shaking, gastro intestinal disturbance, restlessness, defective cognition, decreased heart rate and blood pressure in the case of blood phobia.

Mathophobia refers to "a state of discomfort that occurs in response to situations involving mathematical tasks that are threatening to self-esteem and the panic, helplessness, paralysis, and mental disorganization arising among some people when they are required to solve a mathematical problem " (Bursal and Paznokas, 2006:173). Also, mathophobia is defined as low selfconfidence, a negative mind-set towards mathematics learning (Jain and Dowson, 2009).This, mathophobia, the fear of Mathematics generates a negative response specific to the learning or doing of Mathematical activities 
that interfere with performance (Whyte, 2009). Hence, a disorder that impinges on person's cognitive, affective and physical reaction to mathematical concepts (Freiberg, 2005). Moreover, Zambo and Zambo, (2006:13), "If mathematics makes a student feel anxious... [the learning and teaching of mathematics] will be marked with negative emotions and bodily sensations" and these possibly will have a great and enduring effect on learning the subject.

Asikhia (2014) carried out a study examining the effectiveness of cognitive restructuring on Mathematics anxiety among students in Ogun State. The study employed a 2 × 2 × 3 pre-test, post-test factorial design. The sample consists of 90 males and 90 females of high, medium and low study habit level who were Mathematics anxious based on their responses to the researcher's adopted instruments namely Mathematics Anxiety Rating Scale-Revised (MARS-R) and Study Habit Inventory (SHI) by Bakare (1977). The sample was divided into an experimental and a control group. The experimental group received cognitive restructuring treatment while placebo was administered to the control group. Analysis of covariance was used to test the hypothesis formulated. Results of this study showed a significant effect of treatment of cognitive restructuring on students' level of anxiety in Mathematics (F-ratio= 5.81, P <0.05). Asikhia (2014) used ANCOVA for analysis while the present study used independent sample t-test and paired samples t-test. It is on this basis that this researchers intend to replicate these findings in the management of mathophobia students in Khana Local Government Area of Rivers State.

Okoiye and Falaye (2011) carried out a study that focuses on the effectiveness of cognitive and group behaviour therapies in managing examination anxiety among academically-at-risk students in Ibadan, Oyo State, Nigeria. The study adopted an experimental research design. One hundred and eighty (180) participants from six secondary schools in three LGAs in Ibadan were used. Assignment of subject was done into two experimental and one control groups. The experimental groups were given ten weeks training in cognitive and group behaviour therapies, while no training was provided for those in the control group. Two validated instruments namely Examination Anxiety Scale and Student Academic Self-Efficacy Scale were adopted and used. Data analysis was done using ANCOVA and t-test. The findings indicated that both treatments significantly affected academically-atrisk students to manage examination anxiety. Hence, in the final analysis, cognitive behaviour and group therapies are effective in managing examination anxiety among academically-at-risk-students. On this note, it was recommended among others that the school counsellors could adopt the two interventions therapies. Owing to this result, the researchers had no doubt that this technique would be of enormous help in managing mathophobia among students in Khana Local Government Area of Rivers State. While Okoiye and 
Falaye used ANCOVA AND t-test, the present study used only t-test for data analysis.

Antoni (2003) investigated on anxious students' academic behaviour by using cognitive restructuring to verify if unrealistic self-statements influence academic anxiety, which affects students. In his study, he used 102 students identified as low achievers who were randomly split into experimental and control groups aged between 13-19yrs, with a mean of 16 and systematic desensitization of 9.1. He adopted 5 variables which included teacher experience, self-concept, self-statement, school size and peer group. Analyzed data showed that students who used cognitive restructuring in the treatment group, performed better as it was recorded that their anxiety level reduced and their self-esteem boosted, from their post test results. Also, measures of anxiety from the control group, correlated positively, with their performance recorded on their self-statements. This was, therefore, the reason for reduced performance in school subjects which invariably leads to poor academic achievement. Based on the efficacy of this technique, the researchers intend to use cognitive restructuring in the management of mathophobia among secondary school students in Khana Local Government Area of Rivers State while Antoni (2003) investigated academic anxiety, this study is specific to mathophobia.

\section{Research methodology}

The study adopted a pre-test, post-test and control group quasiexperimental design with the $3 \times 2$ factorial matrix. According to Kpolovie (2010), experimental research is the most powerful and most suitable methodology in investigations for the overt establishment of causal relationships (cause-and-effect relationships) among variables. It ensures dependable specification of the cause of such relationships through control and manipulation of the variables under investigation. In this design, the researchers manipulated one independent variable which is the counselling technique and its effects observed. Two groups were used for the study; one experimental group and one control group. All groups were pretested but only the experimental group which is cognitive restructuring, received treatment on Mathophobia. The control group did not receive any treatment. After the pretest, there was post-test on experimental group on cognitive restructuring.

Table 1:Randomized pretest, post-test and control group

\begin{tabular}{|c|c|c|c|c|c|}
\hline & Group & Pretest & Independent Variable & Post test 1 & Follow up \\
\hline R & E & Q1 & X & 02 & 03 \\
\hline R & E & Q1 & X & 02 & 03 \\
\hline R & C & Q1 & - & 02 & 03 \\
\hline
\end{tabular}




\section{KEY}

$\mathrm{X}=$ The experimental variables (cognitive restructuring and systematic desensitization)

$\mathrm{R}=$ Random assignment of treatment of the groups

$\mathrm{E}=$ Experimental groups

$\mathrm{C}=$ Control group.

$\mathrm{Q} 1=$ Measure before treatment

$02=$ Measure of the dependent variable after treatment

$03=$ Measure of the dependent variable two months after the treatment.

$=$ The control group received no treatment

The population consisted of all the SS2 students in the 22 public secondary schools in Khana Local Government Area. SS2 students numbering 2,425 (Post Primary School Board Bori on the $15^{\text {th }}$ of December, 2016) formed the population. The study sample consisted of 120 SS2 students who indicated phobic-based status as articulated by the Mathophobia Diagnostic Questionnaire that was administered to them by the researchers. Simple random sampling by balloting was used to draw the three co-educational public Secondary Schools in Khana Local Government Area of Rivers State, Nigeria. After the pre-test, the researchers selected 40 participants which comprised of 20 males and 20 females to each of the groups. The Mathophobia Diagnostic Questionnaire (MDQ) which is a 30 -item instrument measuring Mathematics anxiety expressed with statements concerned with one's feelings towards Mathematics. A high index of score suggests anxiety disorder while a low index suggests the reverse. The maximum and minimum score possible were 120 and 30 respectively, and a student with 60 and above was identified as Mathematics phobic. The scale has two sections. Section A is to elicit information on idiographic and demographic variables while section B contains the 30 items of the scale presented in a Likert format of Strongly Agree, Agree, Disagree and Strongly Disagree. The validity of the instrument used for the study relied on vetting by three experts in the field of Educational Psychology, Guidance/Counselling and Measurement and Evaluation in the Department of Educational Psychology, Guidance and Counselling in the University of Port Harcourt, Rivers State, Nigeria. The reliability was carried out by teaching a selected class of students from Tai LGA who were not used for the study. The reliability co-efficient of the instruments was established through test-retest method. The initial and re-test scores were correlated using Pearson Product Moment, hence, coefficient of 0.85. The coefficient value so obtained was high enough to guarantee the use of the instrument as a reliable one for this study.

The procedure for the collection of data involved three stages namely: the pre-test stage, post-test, and follow-up stage. The pre-test stage (first phase): The period involved the preamble and pre-treatment assessment. It 
summed up the base line data for the study. The post-test or post-treatment stage (second phase): The treatment period involved the proper manipulation of the experimental conditions while the follow-up stage (final phase) involved the obtaining of the permanence of treatment effects. The researchers together with two trained assistants at the various phases administered the Mathophobia Diagnostic Questionnaire (MDQ) instrument to the participants. The researchers ensured that procedures were checked to achieve accuracy of 100 percent retrieval of the instrument.

Research questions were answered using descriptive statistics of mean and standard deviation, while hypotheses one and two were tested using independent samples t-test. All analyses were done using SPSS.

\section{Results}

\section{Research Question One}

What is the effect of cognitive restructuring in the management of mathophobia among secondary school students in Khana Local Government Area?

Table 1: Mean and standard deviation of cognitive restructuring effect on mathophobia

$\begin{array}{ccc}\text { Cognitive restructuring } & \text { Mean } & \text { Standard Deviation } \\ \text { Pre-test } & 75.93 & 9.10 \\ \text { Post-test } & 53.25 & 3.97\end{array}$

From the data analysis in table 1, students treated with cognitive restructuring techniques had a lesser mathophobia post-test mean value of $53.25(\mathrm{SD}=9.10)$, compared to their pre-test value of $75.93(\mathrm{SD}=3.97)$. This indicates that cognitive restructuring technique has a positive effect in reducing mathophobia among students in Khana Local Government Area.

\section{Research Question Two}

To what extent is the effect of cognitive restructuring technique in the management of mathophobia among secondary school students in Khana LGA retained after treatment?

Table 2: Mean and standard deviation of cognitive restructuring after treatment and follow

Cognitive restructuring

Post-test

Follow up up

Mean

53.25

55.55
Standard deviation

3.97

4.65

From the data analysis in table 2, students had a lesser post-test mean of 53.25 $\mathrm{SD}=3.97$ ), compared to their follow-up mean of 55.55 ( $\mathrm{SD}=4.65)$. This indicates that the follow-up yielded a higher mathophobic level compared to the post-test. 
Hypothesis one: There is no significant difference between students treated with cognitive restructuring and those in the control group.

Table 3: Independent t-test between cognitive restructure and control group on mathophobia

$\begin{array}{|llrlcccc|}\text { Group } & \mathrm{N} & \text { MEAN } & \text { SD } & \text { Df } & \mathrm{t} & \text { Sig } & \text { Decision } \\ \text { C/R } & 40 & 53.25 & 3.97 & 78 & 23.18 & 0.000 & \text { Reject } \\ \text { Control } & 40 & 81.28 & 6.53 & & & & \text { Ho } 1 \\ \end{array}$

Table 3 shows that the students treated with cognitive restructuring technique had a post-test mean of $53.25(\mathrm{SD}=3.97)$, while the control group had a mean of 81.28 ( $\mathrm{SD}=6.23)$. Further analysis using independent samples $\mathrm{t}$-test yielded $\mathrm{t}(78)=23.18, \mathrm{p}<0.05$. This indicates that a significant difference exists in the mathophobic level of students treated with cognitive restructuring and those in the control group

Hypothesis Two: There is no significant difference in the post and follow-up assessment of students treated with cognitive restructuring technique

Table 4: Paired sample t-test of post and follow-up of cognitive restructuring group

\begin{tabular}{|ccccccccc|}
\hline C/R & $\mathrm{N}$ & Mean & SD & Df & $\mathrm{R}$ & $\mathrm{T}$ & Sig & Decision \\
Post-test & 40 & 53.25 & 3.97 & 39 & 0.77 & 4.28 & 0.00 & Reject \\
$\begin{array}{c}\text { Follow- } \\
\text { up }\end{array}$ & 40 & 55.55 & 4.65 & & & & & HO 1 \\
$(\mathrm{p}<0.05)$
\end{tabular}

Analysis as displayed in table 5, revealed that students treated with cognitive restructuring technique had a posttest mean of $53.25(\mathrm{SD}=3.97)$, while follow-up test had a mean of $55.55(\mathrm{SD}=4.65)$. Further analysis using paired sample t-test, yielded at $(39)=4.28, \mathrm{p}<0.05$. This suggests that a significant difference exists in the post-test and follow-up assessment of students treated with cognitive restructuring technique. Hence, the null hypothesis was rejected.

\section{Discussion of results}

\section{Cognitive Restructuring technique and Mathophobia}

The result obtained from the study revealed that after the application of treatment, students treated with cognitive restructuring technique had a lesser level of mathophobia as shown by their mean $(53.25, \mathrm{SD}=3.97)$, when compared to their pre-treatment level of mathophobia $($ mean $=75.93, \mathrm{SD}=$ 9.10). This shows that the cognitive restructuring has a positive effect mathophobia management among students in Khana Local Government Area of Rivers State, Nigeria.

This result was statistically different from that of the control group. This result obtained from the analysis was expected and not surprising to this researchers because personal observation shows that most students confront 
Mathematics with a negative and irrational mindset believing that they can never learn or master the subject and perform in examination assessments or external examinations. Applying cognitive restructuring technique helps such students to identify the irrational beliefs guiding their approach and perspectives of the subject. This technique can help facilitate their selfconfidence in the subject and help them develop a more positive mindset towards the subject.

This result is similar to that obtained by Asikhia (2014) who found out that cognitive restructuring training was effective in Mathematic anxiety management among students in Ogun State. A similar result was also obtained by Okoiye and Falaye (2011) and Antoni (2003). Despite an extensive literature review, no previous study has yielded a contrary finding.

\section{Recommendations}

From the results obtained, it was recommended as follows-

1. It should be made mandatory for all levels of education to have functional guidance and counselling centers manned by professional counsellors who are competent in cognitive restructuring techniques to assist those who have mathophobia and other maladaptive behaviours.

2. In-service training should be provided to teachers; especially Mathematics teachers so they can readily identify students with mathophobia, and recommend them for counselling.

3. Mathematics teachers should be discouraged from using disparaging comments on students who may not be doing well in the subjects, but assist them in changing their self-defeating thoughts which prevent them from performing optimally in the subjects.

\section{References:}

1. Adesulu, D. (2012). News Analysis: On the Tracks of mass failure in NECO Exams:http://www.vanguardngr.com/2012/04/news-analysison-the-tracks-of-mass-failure-inneco-exams/.

2. Antoni, M. H. (2003). Rational thought replacement. Washington, D. C: APA.

3. Ashcraft, M. H. (2002). Math anxiety: personal, educational and cognitive consequences. Current Directions in Psychological Science, $11,181-185$.

4. Asikhia, O. A. (2014). Effect of cognitive restructuring on the reduction of Mathematics anxiety among senior secondary school students in Ogun State, Nigeria.International Journal of Education and Research, 2(2), 1-20. 
5. Awujo, C. G., Ugwu, C. J. \& Amadi, G. N. (2011). Psychology of phobic disorder for psychotherapists and counsellors. Port Harcourt: University of Port Harcourt Press.

6. Bakare, A. (1977). Study habits inventory. (SHI) Manual Psychoeducational Research Production. Ibadan: University Press.

7. Bamidele, R. (2005). Mathematics not a dreadful subject. Daily Sun Newspaper, August, 30:22.

8. Bursal, M., \& Paznokas, L. (2006). Mathematics anxiety and preservice elementary teacher's conference to teach mathematics and science. School Science and Mathematics, 106,173-180.

9. DiBartolo, P. M., Frost, R.O., Dixon, A. \& Almodovar, S. (2001). Can cognitive restructuring reduce the disruption associated with perfectionist concerns. Behaviour Therapy, 32 (1), 167-184.

10. Eguridu, C. (2013). WAEC 2013 May/June results statistics and performance. www.nigeria school.com.ng.

11. Freiberg, M. (2005). Math - that four-letter word. Academic Exchange Quarterly, 9(3), 7-11.

12. Hall, L. L. (1997). Fighting phobias. FDA Consumer Magazine, 31 (2), 112-120.

13. Jain, S., \& Dowson, M. (2009). Mathematics anxiety as a function of multidimensional self-regulation and self-efficacy. Contemporary Educational Psychology, 34(3), 240-249.

14. Kleinknect R. A. (1986). The anxious staff, diagnosis and treatment of fears and phobia: New York: Human Science Press, Inc.

15. Kpolovie, P. J. (2010). Advanced research methods. Springfield Publishers Ltd: Owerri.

16. Nwankwo, O.C. (2006). Abnormal psychology: Clinical Approach Port Harcourt: Pam Unique Publishers Coy. Ltd

17. Okoiye, O. E., \& Falaye, A. (2011).Effectiveness of Cognitive and Group Behaviour Therapies in Managing Examination Anxiety among Academically-At-Risk Secondary School Students in Ibadan, Oyo State, Nigeria: Journal of Research in Education and Society, 2,2.

18. Perry, A.B. (2004). Decreasing Math anxiety in college students. College Student Journal, 38(2), 19-20.

19. Roedigerill, H. L., Rushton, J. P., Calpaldi, E. D., \& Paris, S.G.(1984). Psychology. Boston: Little Brown and Company.

20. Whyte, J. M. (2009). Maths anxiety: The what, where, and how. Palmerston North: Massey University.

21. Zambo, D., \& Zambo, R. (2006). Using Thought Bubble Pictures to Assess Students' Feelings About Mathematics. Mathematics Teaching in the Middle School, 12(1), 14-21. 